\title{
CONCEPÇÕES DOS ALUNOS DAS ESCOLAS MUNICIPAIS DE CATOLÉ DO ROCHA-PB SOBRE INDISCIPLINA EM SALA DE AULA
}

\author{
Francisco Pereira da SILVA JÚNIOR ${ }^{1}$ \\ Dalila Regina Mota de MELO $^{2}$ \\ Alielson Pereira de SOUSA ${ }^{3}$ \\ Israel Vieira ROCHA ${ }^{4}$ \\ Alane Rayane Sales SOLANO 5
}

\begin{abstract}
${ }^{1}$ Licenciado em Ciências Agrárias - UEPB/CAMPUS IV.junior.leaozinho@ hotmail.com
${ }^{2} \operatorname{Prof}^{\mathrm{a}}$ Dr $^{\mathrm{a}}$ do Departamento de Agrárias e Exatas - UEPB - Campus IV. dalilaregina@ hotmail.com

${ }^{3}$ Licenciado em Ciências Agrárias - UEPB/CAMPUS IV. alielsonpereira@ bol.com.br

${ }^{4}$ Licenciado em Ciências Agrárias - UEPB/CAMPUS IV. rochaisrael@ outlook.com

${ }^{5}$ Licencianda em Ciências Agrárias - UEPB/CAMPUS IV. alanesales@ hotmail.com
\end{abstract}

Recebido em: 17/11/2015 - Aprovado em: 13/07/2016 - Disponibilizado em: 18/12/2016

\begin{abstract}
RESUMO
A indisciplina escolar é fortemente influenciada pela concepção da educação escolar e dos integrantes da escola. Um dos aspectos evidenciados com o estudo é que os problemas de indisciplina escolar, não há ao certo uma causa especifica e nem tão pouco uma solução. Portanto, o presente trabalho teve por objetivo conhecer e analisar a visão dos alunos do ensino fundamental II e médio das escolas públicas de Catolé do Rocha - PB sobre indisciplina em sala de aula. Foi realizado um estudo de caso a partir da coleta dos dados, do qual foi utilizado o método indutivo e como instrumento de pesquisa foi aplicado um formulário contendo dez perguntas e respondidas por sessenta alunos das escolas públicas de Catolé do Rocha- PB. A indisciplina é a mescla com diversos fatores, não podendo deixar de englobar a família, fatores externos e internos da escola. Deve-se compreender o que é indisciplina, tentando buscar em sua concepção o que realmente os alunos fazem de suas atitudes, os alunos agem de acordo com sua idade com seu comportamento que será normal, de uma criança ou um adolescente.
\end{abstract}

Palavras-chave: Indisciplina. Ensino-aprendizagem. Discentes.

\section{ABSTRACT}

The school indiscipline is influenced strongly by the conception of the school education and of the members of the school. One of the aspects evidenced with the study it is that the problems of school indiscipline, there is not to the right a cause it specifies and nor so a little a solution. Therefore, the present work had for objective to know and to analyze the students' of the fundamental teaching vision II and medium of the public schools of Catolé do Rocha - PB on indiscipline in class room. A case study was accomplished starting from the collection of the data, of which the inductive method was used and as research instrument was applied a form containing ten questions and answered by sixty students of the public schools of Catolé do Rocha - PB. The indiscipline is the mixture with several factors, not could stop including the family, external and internal factors of the school. It should be understood what is indiscipline, trying to look for in your conception that the students really do of your attitudes, the students 
act in agreement with your age with your behavior that will be normal, of a child or an adolescent.arting from itself, but knowing the attitudes room remains the same.

Keywords: Indiscipline. Teaching-learning. Students.

\section{INTRODUÇÃO}

A indisciplina vem aumentando constantemente dentro das instituições escolares causando um grande desconforto dentro de sala de aula, preocupando os docentes que tentam buscar algo para prevenir tais comportamentos dos alunos. A presença da indisciplina na sala de aula é algo que incomoda não somente professores, mas também toda comunidade escolar onde todos os envolvidos saem prejudicados dentro do processo ensino aprendizagem. Segundo Oliveira (2005) além de a indisciplina causar danos ao professor o aluno também é prejudicado pelo o seu próprio comportamento, eles não aproveitam nada dos conteúdos ministrados durante as aulas, pois $\mathrm{o}$ barulho e a movimentação impedem qualquer trabalho reprodutivo.

A escola não vem conseguindo desempenhar as mudanças necessárias na vida do aluno, pois sempre estar utilizando métodos repetitivos criando assim um ambiente desagradável dentro de sala de aula, com isso temos como resultado alunos indisciplinados, desmotivados e desinteressados. Para
Britto (2013), “a indisciplina exigem medidas de combate efetivas e urgentes, pois estão, sem dúvida, entre os problemas que mais afetam indistintamente a escola, a formação do cidadão e a sociedade como um todo".

A indisciplina também é gerada devido à metodologia utilizada pelo o professor dentro de sala de aula, pois é necessário o docente criar um clima favorável onde os alunos possam interagir de maneira positiva na aula, este bom clima está relacionado à estrutura, processo de organização, e os comportamentos individuais e em grupos que o estabelecimento oferece.

A família é outra instituição que tem uma responsabilidade primordial na educação base da criança, quanto à formação de caráter. A contribuição da família influencia tanto de forma positiva como também negativa, pois a mesma precisa preservar o seu moral e respeito diante da sociedade, para que os alunos cheguem à escola com a conduta disciplinada, facilitando $\mathrm{o}$ trabalho da instituição escolar. Silva (2008) afirma que a família e a escola, são duas instituições diretamente ligadas ao ser humano em 
desenvolvimento, pois os alunos carregam saberes anteriores adquiridos no seio de sua família, do meio em que vivem que se choca com os saberes docentes, por isso carece interferir de maneira positiva, buscando pontos fundamentais que se efetive este ser de maneira saudável na sociedade presente.

Essa é a grande tarefa dos educadores brasileiros na atualidade, fazer com que os alunos permaneçam na escola e que progridam tanto quantitativa quanto qualitativamente nos estudos. Mesmo porque escolaridade mínima e obrigatória é um direito adquirido de todo aquele nascido neste país. E desse princípio éticopolítico, e também legal, não podemos abrir mão sobre hipótese nenhuma. A indisciplina também é uma responsabilidade dos pais, há uma dificuldade em educar tanto da parte dos docentes como da família, pois historicamente são as duas principais vias responsáveis pela educação de crianças e jovens (AQUINO, 2003).

Portanto, o presente trabalho teve por objetivo conhecer e analisar a visão dos alunos do ensino fundamental II e médio das escolas municipais de Catolé do Rocha - PB sobre indisciplina em sala de aula.

\section{MATERIAL E MÉTODOS}

A pesquisa foi realizada no mês de outubro de 2014 com alunos das escolas Centro de Ensino Fundamental Luzia Maia, Professora Catarina de Sousa Maia e da Escola Estadual de Ensino Fundamental e Médio Obdúlia Dantas, a qual está funcionando na Escola Estadual de Ensino Fundamental João Suassuna. Todas localizadas na zona urbana do município de Catolé do Rocha-PB.

Foi realizado um estudo de caso a partir da coleta dos dados, do qual foi utilizado o método indutivo e como instrumento de pesquisa foi aplicado um formulário contendo 10 perguntas adaptadas de Baptista (2011), das quais foram: Indisciplina é a discordância entre o que o professor espera e o que o aluno faz? Indisciplina é responsabilidade do professor? Um professor com atitude autoritária consegue conter a indisciplina em sala de aula? A família também pode ser responsável pelo os atos de indisciplina dos alunos que ocorrem na sala de aula? Como um professor deve agir em sala com indisciplina? Indisciplina e responsabilidade do aluno? Em relação à indisciplina em sala de aula como você se auto avalia? Você respeita seus 
pais? Você acha que recebe bons exemplos de seus pais? Você concorda com as regras exposta pela sua escola?.

O formulário foi aplicado a 60 alunos, sendo uma amostra de 20 alunos em cada escola, das séries $9^{\circ}$ do ensino fundamental e $3^{\circ}$ ano do ensino médio, com faixa etária de idade de 14 a 17 anos. Logo após a coleta de dados, as respostas dos alunos entrevistados, foram analisadas de forma individual e coletiva.

\section{RESULTADOS E DISCUSSÃO}

Diante dos resultados, observase que em resposta a primeira pergunta a maior parte dos alunos setenta por cento $(70 \%)$ concordaram fortemente que a indisciplina é a discordância do que o professor espera do aluno e trinta por cento (30\%) dos alunos concordaram em partes (Gráfico1). A maioria dos alunos concordou devido está praticando constantemente essa indisciplina dentro de sala de aula, pois estão sempre discordando das opiniões dos professores causando um desconforto no ambiente escolar e dificultando cada vez mais o trabalho do professor.
Gráfico 1 - Pergunta 1: Indisciplina é a discordância entre o que o professor espera e o que aluno faz? UEPB, Catolé do Rocha-PB, 2014.

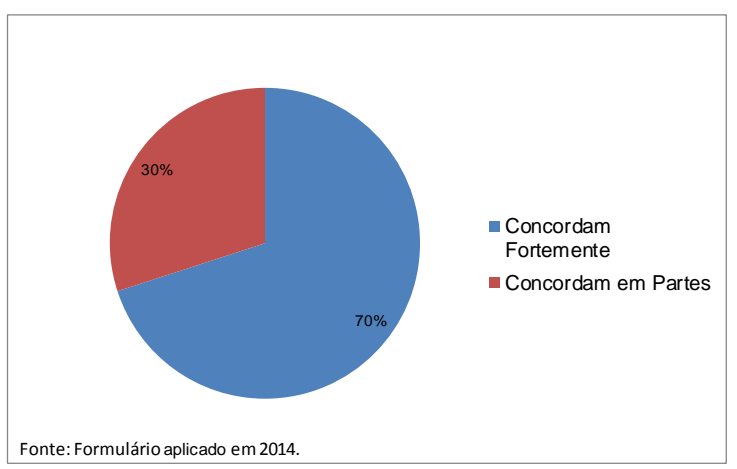

Assim como para Garcia (1999), a indisciplina pode englobar vários aspectos escolares, é definida como a desarmonia entre os critérios e expectativas assumidos pela escola, em termos de comportamento, atitudes, socialização, relacionamento e desenvolvimentos cognitivo e tudo aquilo que os estudantes demonstram.

Em resposta a segunda questão, cinquenta por cento $(50 \%)$ dos alunos discordaram colocando a maior parte da responsabilidade da indisciplina no aluno, já trinta por cento (30\%) concordaram em partes, afirmando que o professor também contribui para essa indisciplina e dezessete por cento (20\%) concordaram fortemente que é responsabilidade do professor (Gráfico 2). A responsabilidade da indisciplina é de todos os envolvidos na educação 
escolar, então não pode-se deixar de englobar a família a escola e o próprio aluno. A relação da indisciplina também é influenciada pelo o meio social que está inserido o aluno, pela metodologia aplicada pelo professor dentro de sala de aula.

Gráfico 2 - Pergunta 2: Indisciplina é responsabilidade do professor? UEPB, Catolé do Rocha-PB, 2014.

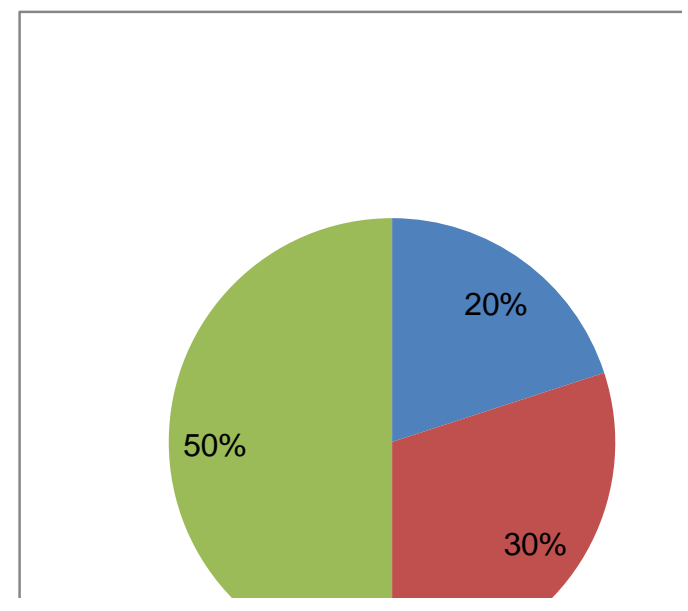

Desta forma, Freire (1997, p.60) afirma que a afetividade por parte do professor não abdica de sua responsabilidade e de sua autoridade. Ressalta que a prática educativa vivida com alegria e afetividade não prescinde da formação científica séria e da clareza política dos educadores. Enquanto os professores não perceberem que é, também através da dinâmica relacional do docente com a turma e da análise detalhada do que se passa no seio do grupo que podem melhorar o ambiente da sala de aula, não obterão grandes resultados.

Para a pergunta três, oitenta por cento $(80 \%)$ dos alunos entrevistados concordaram fortemente que um professor com atitude autoritária consegue impor respeito e conter a indisciplina dos alunos, vinte por cento (20\%) discordaram da atitude de um professor autoritário (Gráfico 3). O docente precisa ter autoridade em sala de aula, pois isso facilita o seu trabalho no ambiente escolar, mas é necessário que haja um equilíbrio nessa autoridade para não causar constrangimentos nos alunos, mas sim causar um respeito mutuo entre ambos.

Gráfico 3 - Pergunta 3: Um professor com atitude autoritária consegue conter a indisciplina em sala de aula? UEPB, Catolé

do Rocha-PB, 2014.

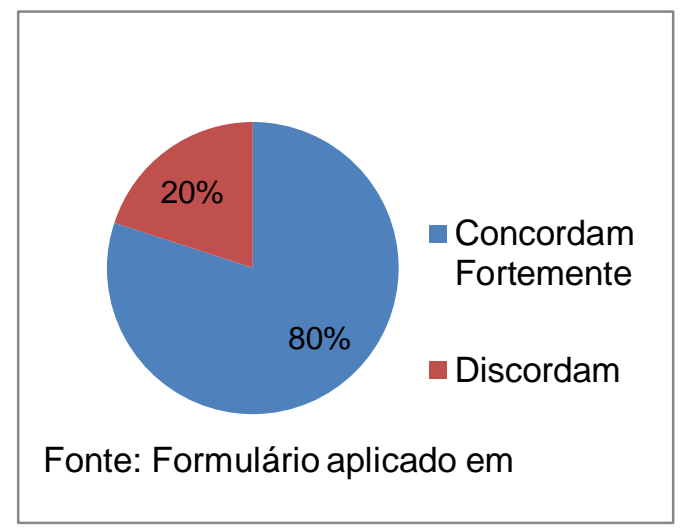


De acordo com Luna (1991) enfatiza que o professor com autoridade é aquele que deixa transparecer as razões pelas quais as exercem: não por prazer, não por capricho, nem mesmo por interesse pessoal, mais por um compromisso genuíno com o processo pedagógico, ou seja, com a construção de sujeitos que, conhecendo a realidade, disponha-se a modificá-la em consequência com um sujeito.

Em resposta a pergunta de número quatro, setenta por cento $(70 \%)$ dos alunos concordaram fortemente que a relação família e aluno está fortemente ligada a indisciplina. Já trinta por cento (30\%) concordaram em partes que a família contribui também para atos indisciplinares (Gráfico 4). A família é a base da educação de todo ser humano, pois se essa faz a sua função de forma significativa com certeza o aluno vai se desenvolver bem na escola, pois todo ser humano precisa de um acompanhamento quando está em desenvolvimento.
Gráfico 4 - Pergunta 4: A família também pode ser responsável pelos atos de indisciplina dos alunos que ocorrem na sala de aula? UEPB, Catolé do Rocha-PB, 2014.

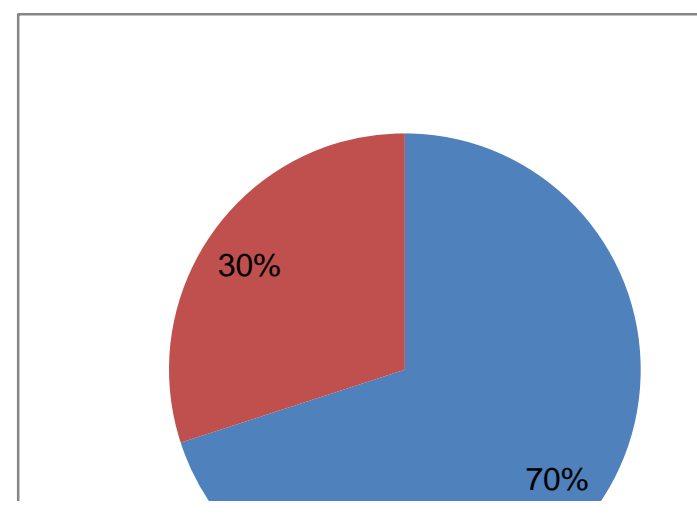

Esse resultado pode ser confirmado segundo Aquino (2003), que diz que a indisciplina não e um problema que vem somente da relação professor e aluno, e tampouco somente dos alunos, e nem somente da escola em geral. Ainda segundo o autor a indisciplina também e responsabilidade dos pais, há uma dificuldade em educar tanto da parte dos docentes como da família, pois historicamente são as duas principais vias responsáveis pela educação de crianças e jovens.

Dos alunos entrevistados, na questão de número cinco a maioria sessenta por cento $(60 \%)$ optou por uma aula mais interessante. Já outros quarenta por cento $(40 \%)$ preferem um dialogo diretamente entre professor e aluno (Gráfico 5). 
Gráfico 5 - Pergunta 5: Como um professor deve agir em sala com indisciplina? UEPB, Catolé do RochaPB, 2014.

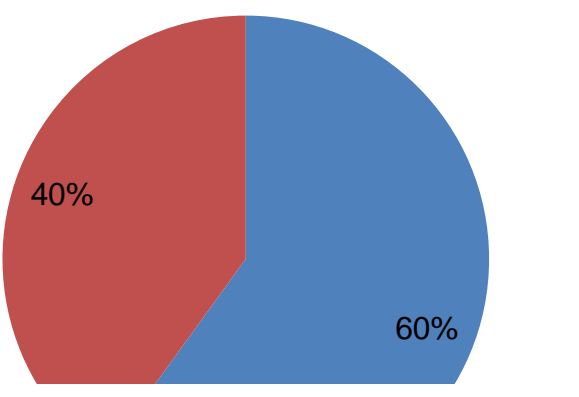

Todo professor precisa conhecer a turma que está trabalhando, melhorar a sua metodologia de ensino para amenizar a indisciplina na sala de aula e caso a mesma venha ocorrer constantemente é necessário pensar em uma forma de punição que deve ser aplicada no aluno, pois caso haja de forma incorreta com essa punição, com certeza prejudicará o ensino e aprendizagem de seus discentes. Porém, não somente a conduta deve ser dos alunos, mas os professores devem ter uma conduta relevante, tentando interagir os alunos com o conteúdo, tornar a aula mais interessante possível com atividade de campo, atividades práticas, presente na vida cotidiana, são recursos metodológicos aos quais os professores lançam para controlar o comportamento dos alunos, afirma-se que assim eles aprendem mais, compreende melhor a matéria, permanecem atentos as aulas (SILVA et al., 2001).

Em resposta a pergunta seis, cinquenta por cento $(50 \%)$ dos alunos entrevistados disseram que a responsabilidade da indisciplina é do próprio aluno. Já os outros cinquenta por cento $(50 \%)$ concordaram em partes achando que a indisciplina esta relacionada a outros meios como metodologia do professor e ao meio social que o aluno está inserido (Gráfico 6). A indisciplina do aluno é gerada devido ao ambiente em que está inserido o aluno a metodologia utilizada pelo professor em sala de aula, o mau gerenciamento das instituições escolares e o descuido de algumas famílias com os seus filhos.

Gráfico 6 - Pergunta 6: Indisciplina e responsabilidade do aluno? UEPB, Catolé do Rocha-PB, 2014.

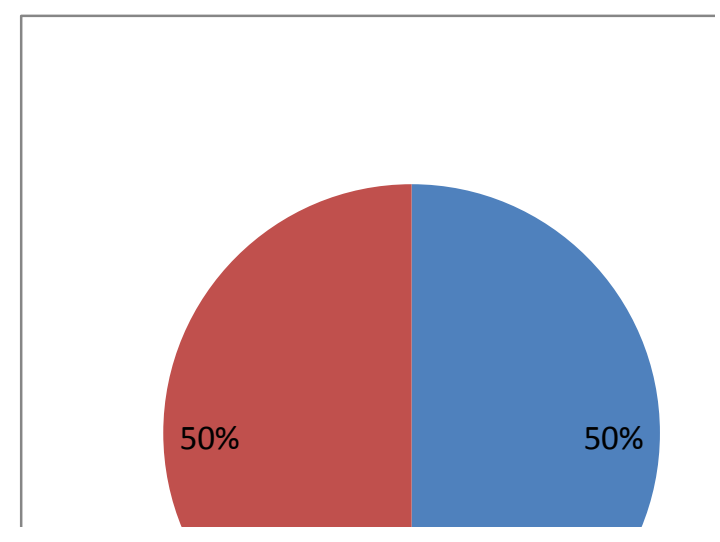


Para Passos (1996, p. 118) as expressões de indisciplina podem estar relacionadas á criatividade, á ousadia, ou á resistência por parte do aluno em relação aos padrões escolares. Acrescenta, que o ato pedagógico, enquanto momento de construção de conhecimento é o momento de emergir falar, movimentos, rebeldia, oposição e o da ânsia por descobrir e por construir juntos, professores e alunos.

$\mathrm{Na}$ questão número sete cinquenta por cento $(50 \%)$ dos alunos entrevistados responderam que são comportados em sala de aula e outros cinquenta por cento $(50 \%)$ disseram que não tem um bom comportamento em sala de aula (Gráfico 7). O mau comportamento dos alunos em sala de aula, causa um grande prejuízo dentro do processo ensino aprendizagem, sendo $\mathrm{o}$ próprio aluno $\mathrm{o}$ mais prejudicado, pois devido esse comportamento afeta de maneira significativa o seu rendimento na aula, ficando assim algumas lacunas vazias do conteúdo ministrado pelo o professor em sala de aula.
Gráfico 7 - Pergunta 7: Em relação à indisciplina em sala de aula, como você si auto avalia? UEPB, Catolé do RochaPB, 2014.

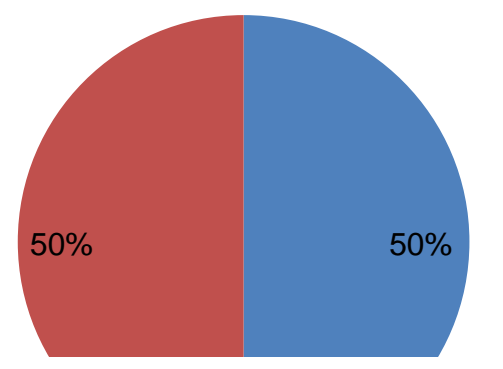

Para Junior e Filho (2001), a sociedade está cada vez mais espantada e preocupada com os comportamentos que os jovens estão apresentando frente ao mundo moderno, é uma das causas desse fato é que os pais e educadores e a escola tentam atribuir as responsabilidades a outrem, mas se esquecem de que os jovens precisam a cima de tudo viver um bom ambiente familiar, que não estejam alterados nem desestruturados.

Em resposta a pergunta oito, oitenta por cento (80\%) dos alunos entrevistados afirmam que respeitam seus pais, e vinte por cento (20\%) disseram que não respeitam (Gráfico 8). Esses dados mostram um excelente resultado onde de certa forma facilita o 
docente de sala de aula a partir do respeito familiar.

Gráfico 8 - Pergunta 8: Você respeita seus pais? UEPB, Catolé do Rocha-PB, 2014.

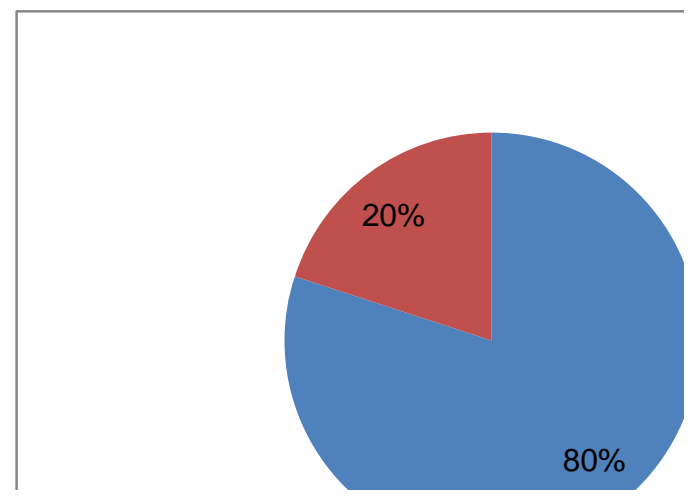

Segundo Nunes (2008, p.1), a família constitui o berço do processo de ensino aprendizagem de todos ser humano nele o aprendiz estar sujeito a ser influenciado decisivamente de forma positiva ou negativa. A escola é frequentada por aqueles que tiveram uma boa formação na família, como também por pessoas que tiveram experiências negativas, gerando assim uma grande diversidade de aluno na sala de aula.

Já a questão de número nove, cinquenta por cento $(50 \%)$ dos discentes entrevistados afirmaram que recebem bons exemplos e que procuram seguir os passos da família e outros cinquenta por cento $(50 \%)$ discordaram afirmando que os pais não os passam bons exemplos a eles a ser seguidos (Gráfico 9). A educação de crianças e jovens tem que partir da família devida ser a principal via que está diretamente ligada ao aluno, caso os pais utilizem bons modos com certeza os seus filhos se comportará da mesma maneira, exercendo assim um papel coerente na sociedade e dentro de sala de aula.

Gráfico 9 - Pergunta: Você acha que recebe bons exemplos de seus pais? UEPB, Catolé do Rocha-PB, 2014.

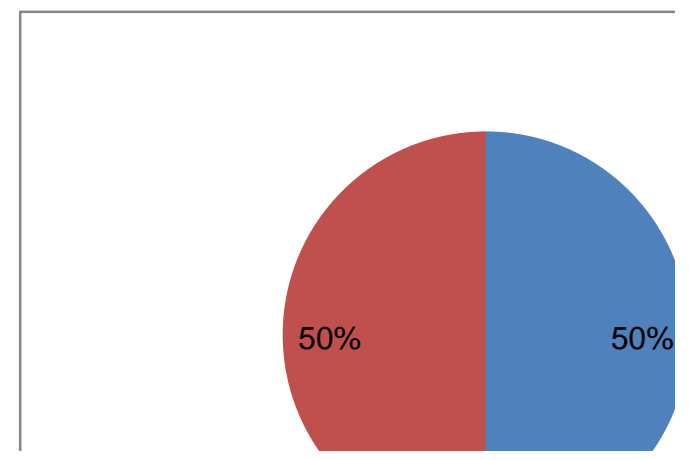

Desta forma afirma, Tiba (1996) afirma que muitos pais complicam sua vida porque nunca cobram nada e de repente, porque seu filho vai mal à escola, resolvem cobrar tudo de uma vez. "Não vou criar um vagabundo" dizem eles, desse "grito de guerra" nasce um monte de regra e exigências.

Para a pergunta dez cinquenta por cento $(50 \%)$ concordaram com as regras que estão sendo impostas por suas escolas e outros cinquenta por 
cento (50\%) discordaram, pois acham que muitas regras que estão sendo impostas ao invés de ajudar estão atrapalhando o ensino aprendizagem (Gráfico 10). As regras expostas pelas as escolas são de fundamental importância na vida de todo estudante, pois é através dessas regras que se consegue alunos disciplinados que expressam um bom comportamento em diversos meios sociais. Já Giancanterino (2007, p.87) afirma que a indisciplina em sala de aula e na escola tem sido uma preocupação crescente nos últimos anos entre os educadores. Os grandes responsáveis pela educação de jovens, como a família e a escola, não estão sabendo ou conseguindo cumprir o seu papel.

Gráfico 10 - Pergunta 10: Você concorda com as regras expostas pela sua escola? UEPB, Catolé do RochaPB, 2014.

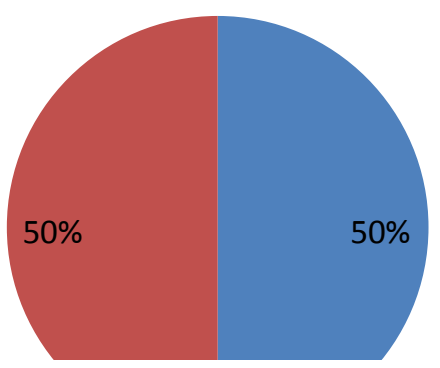

\section{CONCLUSÃO}

Diante das concepções dos alunos sobre a questão da indisciplina em sala de aula, os dados constam que vários fatores influenciam nesse mau comportamento em sala, as respostas das questões propostas ao longo desta pesquisa dão conta que a grande maioria dos alunos não sabe definir claramente esse tipo de atitude. $\mathrm{Na}$ maioria das vezes essas atitudes indisciplinares são por motivos que englobam várias questões, como por exemplo, fatores externos e internos da escola, a família também seria um deles e o ambiente social no qual estão inseridos também influencia de forma direta.

Deve-se compreender o que é indisciplina, tentando buscar em sua concepção o que realmente os alunos fazem de suas atitudes, os alunos agem de acordo com sua idade com seu comportamento que será normal, de uma criança ou um adolescente.

\section{REFERÊNCIAS}

AQUINO, J. G. A Indisciplina: o contraponto das escolas democráticas. São Paulo. Editora Moderna. 2003.

BAPTISTA. J. D. Concepções dos alunos e de um docente em relação ás atitudes disciplinares em sala de aula. 
2011. 52 f. Monografia (Graduação em Ciências Biológicas) - Universidade Presbiteriana Mackenzie São Paulo, 2011. BRITTO, A. C. O. Indisciplina na sala de aula: contribuições da análise do comportamento. 2013. 71p. Monografia (graduação em Pedagogia) Centro Universitário Católico Salesiano Auxilium - UNISALESIANO, Lins-SP, 2013.

FREIRE, P. Pedagogia da autonomia: saberes necessários á pratica educativa. 6 a Ed. . Rio de Janeiro: Paz e Terra. 1996.

FREIRE, P. Pedagogia da autonomia: saberes necessários á pratica educativa. $6^{\text {a }}$ Ed. . São Paulo: Paz e Terra. 1997.

GARCIA, J. Indisciplina na escola: uma reflexão sobre a dimensão preventiva. Curitiba. Revista Paranaense de Desenvolvimento, Curitiba, n. 95, p. 101-108, jan./abr. 1999.

GIANCANTERINO, R. Escola, professor, aluno: Os participantes do processo educacional. São Paulo: Madros, 2007.

JUNIOR, G. A. F.; FILHO, J. X. Reflexões sobre a indisciplina e a agressividade na escola atual. In: VASCONCELOS et al. (In)disciplina, escola e contemporaneidade. São Paulo. Editora Mackenzie. 2001. p 2739.

LUNA, S. D. C. A questão da autoridade na educação. In: Caderno de pesquisa. São Paulo. Fundação Carlos Chagas, 1991.

NUNES, A. Indisciplina na sala de aula - Uma reflexão a partir da realidade,Disponível: $<$ http://www.ase mana.publ.cv/spip.php?article17387\&v ar_recherche=indisciplina $\% 20$ na $\% 20$ sal a\%20de\%20aula\&ak=1>. Acesso em: 27/11/2014.

OLIVEIRA, M. I. Indisciplina escolar: determinações, consequências e ações Brasília: Líber livro, 2005.

PASSOS, L. F. A indisciplina e o cotidiano escolar: novas abordagens, novos significados. In: AQUINO, J. G. (Org.). Indisciplina na escola: alternativas teóricas e práticas. 8. ed. São Paulo: Summus, 1996. p. 117-127. SILVA, G. T. Família e Escola: Juntas para o fortalecimento de seu papel.

Disponível em: htpp:// www.artigos.com 2008.

SILVA, A. M.; R, A.B.; L, S. Problemas disciplinares mais frequentes e suas causas: a visão do professor. In: VASCONCELOS et al. (In)disciplina, escola e contemporaneidade . São Paulo. Editora Mackenzie. 2001. p 77 91.

TIBA, I. Disciplina, limites na medida certa. São Paulo: Editora gente; $1^{\circ} \mathrm{Ed}$, 1996. 